\title{
Escola conveniada ou charter school? Uma abordagem sobre termo de colaboração entre a prefeitura e o terceiro setor para oferta da educação básica em Porto Alegre
}

\author{
Accredited school or charter school? An approach to a term of collaboration between prefecture \\ and the third sector for the offer of basic education in Porto Alegre
}

¿Escuela acretidada o escuela charter? Un enfoque de un plan colaborativo entre la prefecturay
el tercer sector para la oferta de la educación básica en Porto Alegre

Altair Alberto Fávero
Daniela de Oliveira Pires $^{* *}$
Evandro Consaltér $^{* * *}$

\section{Resumo}

O presente estudo analisa se as parcerias firmadas entre o Poder Público e o Terceiro Setor para a oferta de educação básica podem ser configuradas como modalidades de escola charter. Em particular, aborda Termo de Colaboração firmado entre a Prefeitura de Porto Alegre e uma Organização da Sociedade Civil. Além disso, analisa como o Marco Regulatório do Terceiro Setor pode servir de aporte para a perpetração do setor privado sobre o setor púbico na área da educação através de termos de colaboração entre o Poder Público o Terceiro Setor. 0 estudo caracteriza-se como qualitativo, valendo-se de dados bibliográficos e documentais, ancorado no método dedutivo-analítico. Como resultados, aponta que as parcerias analisadas podem ser comparadas às escolas charter, embora a nomenclatura diferenciada. Além disso, representam uma concepção de educação que se afasta do ideário da gestão democrática, do exercício da cidadania e da emancipação social.

Palavras-chave: Escolas Charter. Marco Regulatório. Terceiro Setor. Parceria Público-Privadas.

Recebido em 07/05/2019 - Aprovado em 17/09/2019

http://dx.doi.org/10.5335/rep.v27i1.10577

Doutor em Educação pela Universidade Federal do Rio Grande do Sul (Ufrgs, Brasil) com pós-doutoramento (Bolsista Capes) pela Universidad Autónoma del Estado de México (UAE-México). Atua como professor e pesquisador no Curso de Filosofia, no Mestrado e Doutorado em Educação da Universidade de Passo Fundo (UPF, Brasil). ORCID https:// orcid.org/0000-0002-9187-7283. E-mail: altairfavero@gmail.com

** Professora Adjunta da Universidade Federal do Paraná (UFPR, Brasil). Doutora em Educação pela Universidade Federal do Rio Grande do Sul (Ufrgs, Brasil). ORCID https://orcid.org/0000-0003-2755-4911. E-mail: danielaopires77@ gmail.com

*** Doutorando em Educação (Bolsista Capes) pela Universidade de Passo Fundo (UPF, Brasil). Pesquisador e vice-coordenador do Grupo de Estudos e Pesquisas sobre Educação Superior - Gepes, vinculado ao Programa de Pós-Graduação em Educação da Universidade de Passo Fundo (Brasil) e ao Grupo Internacional de Estudos e Pesquisas sobre Educação Superior - Giepes, com sede na Universidade de Campinas (Unicamp, Brasil). ORCID https://orcid.org/00000001-8798-8960. E-mail: evandroconsalter@gmail.com 


\section{Abstract}

The present study analyzes if the partnerships established between the Government and the Third Sector for the provision of basic education can be configured as a charter school modality. In particular, it deals with a Collaboration Agreement signed by the Porto Alegre City Hall and a Civil Society Organization. It also analyzes how the Third Sector Regulatory Framework can serve as a contribution to the perpetration of the private sector over the public sector in the area of education through terms of collaboration between the Government and the Third Sector. The study is characterized as qualitative, using bibliographic and documentary data, anchored in the deductive-analytical method. As a result, it points out that the analyzed partnerships can be compared to charter schools, although the different nomenclature. Moreover, they represent a conception of education that is far from the ideal of democratic management, the exercise of citizenship and social emancipation.

Keywords: Charter Schools. Regulation Mark. Third Sector. Public-Private Partnership.

\section{Resumen}

El presente estudio analiza si las alianzas establecidas entre el Gobierno y el Tercer Sector para la provisión de educación básica pueden configurarse como modalidades de escuela charter. En particular, se trata de un Acuerdo de Colaboración firmado por la Prefectura de Porto Alegre y una Organización de la Sociedad Civil. También analiza cómo el Marco Regulatorio del Tercer Sector puede servir como una contribución a la perpetración del sector privado sobre el sector público en el área de la educación a través de los términos de colaboración entre el Gobierno y el Tercer Sector. El estudio se caracteriza por ser cualitativo, utilizando datos bibliográficos y documentales, anclados en el método deductivo-analítico. Como resultado, señala que las asociaciones analizadas se pueden comparar con las escuelas charter, aunque la nomenclatura es diferente. Además, representan una concepción de la educación que parte del ideal de la gestión democrática, el ejercicio de la ciudadanía y la emancipación social.

Palabras clave: Escuelas Charter. Marco Regulatorio. Tercer Sector. Asociación Público-Privadas.

\section{Introdução}

Muito disseminadas nos Estados Unidos, as charter schools, introduzidas inicialmente em Minnesota, em 1992, são financiadas com dinheiro público, mas gerenciadas de forma privada. Segundo Abrams (2016), essa modalidade de escola consolida as ideias de Friedman, que há décadas já recomendava que operadores com fins lucrativos administrassem escolas públicas como critério para elevar a qualidade do ensino. Abrams (2016) elenca uma série de empresas especializadas em administrar escolas americanas com fundos públicos. Entre as maiores, destaca a Edison Schools Inc., com sede no décimo quinto andar de uma torre de escritórios em Manhattan. Em 2001, a Edison já administrava uma rede de 114 escolas com 74.000 estudantes em 23 estados. Um pouco mais da metade dessas escolas eram escolas distritais, enquanto o restante eram escolas charter.

Empresas como a Edison passaram a ser conhecidas como Educational Management Organizations (Organizações de Gerenciamento Educacional), ou apenas 
EMOs. Conforme Abrams (2016), as EMOs eram uma resposta da educação às Health Maintenance Organizations (Organizações de Manutenção de Saúde), ou HMOs, muito comuns na época por administrarem com fundos públicos setores da saúde. Com o mesmo escopo, as EMOs operavam o propósito de "melhorar o serviço, conter custos e, em muitos casos, obter lucro" (ABRAMS, 2016, p. 9, tradução dos autores). Hoje, as escolas charter americanas compõem um universo de mais de 6 mil escolas em 42 estados.

O que Abrams (2016) destaca da experiência americana, Bunar (2012) também evidencia em seus estudos sobre o sistema educacional da Suécia, outro país que apostou muito em um modelo descentralizado e nas Charter Schools. Ambos constatam que, embora os aparentes resultados positivos das avaliações e rankings nacionais e das enfáticas defesas desses sistemas como modelos modernos e mais eficazes, há elementos negativos a serem considerados. Conforme os autores, o estresse ligado à escolha da escola pela família, o tempo excessivo dedicado ao marketing e a inflação de notas, como forma de melhorar a posição de uma escola no mercado resultaram em significativos indicadores de aumento de mecanismos socialmente injustos e segregadores do sistema educacional, que em sua construção socio-histórica deveria conceber uma educação pautada pelo princípio do bem comum (DARDOT; LAVAL, 2017).

Apesar de outros países latino americanos terem experienciado essa modalidade escolar em maior escala, como é o caso do Chile (ELACQUA, 2009) e da Colômbia (EDWARDS JR.; HALL, 2017), no Brasil, pouco se tem registrado sobre tal temática ou iniciativas dessa natureza organizacional. Sardinha (2013) cita o exemplo de uma breve tentativa em Pernambuco, entre os anos de 2005 e 2007, por meio de um projeto denominado "Procentro", uma parceria entre o governo do estado, municípios e a Fundação Itaú Social (SARDINHA, 2013, p.79).

A escassez de registros de tal iniciativa no Brasil é constatada por Adrião (2014), que em levantamento sobre publicações brasileiras no Scielo e Banco de Tese da Capes, referentes ao período de 1990 a 2012, que tenham adotado como palavras-chave (descritores) os termos charter ou choice associadas à educação, constatou a inexistência de publicações sobre a temática. No entanto, Adrião (2014) ressalta que, de outro modo, o que a literatura e os manuais consultados para a pesquisa realizada caracterizam por charter pode englobar tanto escolas públicas geridas por instituições privadas, quanto escolas privadas subsidiadas por fundos públicos. Todavia, "as condições exigidas para que tais escolas sejam charter é que não haja cobrança de mensalidades ou matrículas, que operem segundo as normas 
estabelecidas pelos setores responsáveis e que possam ser escolhidas pelas famílias" (ADRIÃO, 2014, p. 278).

Dessa forma, o estudo de Adrião (2014) questiona se não seriam as escolas "conveniadas" brasileiras, tão disseminadas e mesmo induzidas por diversos programas governamentais para o atendimento da educação básica uma modalidade de charter? Além disso, não estaríamos a vivenciar essa experiência com outra designação e para a qual as desigualdades observadas são objetos de estudos e denúncias?

É importante destacarmos que essas parcerias se acentuaram, sobretudo, a partir do novo marco regulatório do terceiro setor, por meio da Lei $n^{0}$ 13.019/14, que cria as Organizações da Sociedade Civil - OSC. Por intermédio da nova legislação e de leis anteriores que continuam regulando boa parte dessas parcerias, como a chamada Lei das Organizações Sociais (Lei 9.637 de 15 de maio de 1998), entidades de caráter privado, mas que ganham esse status social caso cumpram uma série de requisitos, como eficácia comprovada e fins sociais, o poder público acaba não conseguindo exercer uma fiscalização e um monitoramento adequado dessas relações, tendo em vista a sua complexidade. Essa nova legislação (OSC) começou a vigorar em janeiro de 2016, nos âmbitos da União, Estados e Distrito Federal. Para os municípios, foi estabelecido o início de sua vigência para $1^{\circ}$ de janeiro de 2017. É importante frisar que nesse novo modelo de parceria, a gestão das finanças, a contratação de professores e as questões pedagógicas são de responsabilidade do parceiro privado.

Um exemplo dessas parcerias é o projeto piloto desenvolvido pela prefeitura do município de Porto Alegre - Rio Grande do Sul/Brasil - em 2018, por meio de uma parceria público-privada (a primeira do município para esta finalidade) para o atendimento de 350 alunos de Ensino Fundamental na Escola Pequena Casa da Criança, no Bairro Partenon. Para a viabilidade do projeto, o governo municipal repassa à entidade mantenedora da escola recursos públicos no valor mensal de $\mathrm{R} \$$ : 452,00 por aluno. O termo de colaboração assinado entre a prefeitura e a entidade terá vigência de 5 anos, prorrogável por igual período.

Diante desse cenário e dos questionamentos de Adrião (2014), propomos neste estudo, primeiramente, uma análise de como o marco regulatório do terceiro setor pode servir de aporte para a perpetração do setor privado sobre o púbico na área da educação. Além disso, se as parcerias firmadas entre o setor público e o terceiro setor para a oferta de educação infantil e ensino fundamental podem ser configuradas como modalidades de escola charter, assim como as abordadas por Abrams (2016) e como sugerido por Adrião (2014). Em seguida, nosso esforço será em ana- 
lisar o termo de colaboração assinado entre a prefeitura de Porto Alegre e a ONG mantenedora da Escola Pequena Casa da Criança. Observaremos, em especial, os aspetos relacionados à gestão das finanças, à contratação de professores e às questões pedagógicas.

Entendemos que sob o discurso de oferecer uma educação de melhor qualidade, essas parcerias podem ocorrer menos como alternativa democratizadora, de oferta de uma educação de qualidade para todas as crianças e mais como mecanismo de ampliação do mercado educacional. Tentaremos debater essa realidade e com base nos resultados, lançar e reforçar olhares críticos e propositivos sobre programas governamentais para a educação que flertam com setores privados.

\section{0 marco regulatório do terceiro setor como aporte para a perpetração do setor privado sobre o setor púbico na área da educação}

As parcerias público-privadas na educação, amplamente difundidas a partir dos anos 1990, foram estimuladas pela orientação política e econômica neoliberal, mas fundamentalmente pela terceira via. A terceira via foi relacionada ao novo trabalhismo inglês, que sucedeu a política inglesa anterior de Margareth Thatcher. De acordo com Anthony Giddens, tal orientação se coloca entre a antiga socialdemocracia e o neoliberalismo, pois pretende "adaptar a socialdemocracia a um mundo que se transformou fundamentalmente ao longo das duas ou três últimas décadas" (GIDDENS, 2001, p. 36). Dentre as suas premissas constam, a presença do voluntariado, a desresponsabilização da esfera estatal para com os direitos sociais, a meritocracia nas questões da avaliação escolar e a responsabilidade pela execução da sociedade civil, sendo efetivadas por meio das entidades do chamado terceiro setor.

Tal contexto acaba por estimular novas regulamentações entre a esfera pública e a privada. Nesse sentido, ao prevalecer a sociedade de tipo solidária e voluntariosa, identificada pela terceira via como a sociedade civil ativa, tem-se o fortalecimento da relação entre o público e o privado, no qual o poder público financia, na maioria das vezes, a prestação das políticas sociais, que são executadas seguindo uma lógica privatista, estimulando assim, a "mercantilização dos direitos sociais". Setores da sociedade mercantil passam a vincular-se às organizações do terceiro setor, legalmente reconhecidas, firmando parcerias com o poder público, agindo no cumprimento das obrigações que o último deixa de executar. Para Lucia Bruno, 
[...] falam e procuram justificar a redução dos investimentos estatais nas políticas sociais, transferindo parte da responsabilidade sobre esses serviços para a própria classe trabalhadora, que além de sua jornada de trabalho diária (quando a tem), deve também assumir uma segunda, durante a qual haverá de produzir para si mesma aquilo que o Estado desobrigou-se de fornecer-lhe. Outra parte desses serviços é transferida para o setor privado, onde estes são produzidos como mercadoria, operando-se assim a expansão do mercado de bens e serviços consumidos pela classe trabalhadora. Esse processo é bastante visível no caso da educação (BRUNO, 2002, p. 27).

Em que pese, quem passa a controlar a promoção das políticas sociais, seja a direção, ou ainda, a direção e a execução são uma parcela do setor privado identificado com os valores do mercado. É exatamente o que acorre quando do advento das parcerias firmadas entre a esfera pública e o terceiro setor. Tais entidades, regulamentadas pelo próprio Estado brasileiro, por meio da aprovação de duas legislações infraconstitucionais, a das Organizações Sociais - OS e das Organizações da Sociedade Civil de Interesse Público - OSCIPs. A lei das OS foi instituída pela Medida Provisória no 1.591, de 09 de outubro de 1997, posteriormente convertida na Lei Federal no 9.637, de 15 de maio de 1998. De acordo com o artigo 20 do diploma legal assinalado, deveriam ser criados, mediante decreto do Poder Executivo, o Programa Nacional de Publicização (PNP), com o objetivo de estabelecer diretrizes e critérios para a qualificação de organizações sociais. Isso tinha o fim de assegurar a absorção de atividades desenvolvidas por entidades ou órgãos públicos da União, que atuassem nas atividades referidas no artigo $1^{\circ}$, por organizações sociais, qualificadas na forma de lei, observadas as seguintes diretrizes: I - ênfase no atendimento do cidadão cliente; II - ênfase nos resultados, qualitativos e quantitativos nos prazos pactuados; III - controle social das ações de forma transparente.

A legislação das OSCIPs é a de nº 9.790, de 23 de março de 1999, no qual também institui e disciplina o termo de parceria. Podem solicitar a qualificação como OSCIP, as pessoas jurídicas de direito privado, sem fins lucrativos, que tenham pelo menos uma das seguintes finalidades (art. $3^{\circ}$, da Lei $n^{\circ}$. 9.790/99): promoção da assistência social; promoção da cultura, defesa e conservação do patrimônio histórico e artístico; promoção gratuita da educação, ou saúde, observando-se a forma complementar de participação das organizações de que trata esta lei; promoção da segurança alimentar e nutricional; defesa, preservação e conservação do meio ambiente e promoção do desenvolvimento sustentável; promoção do voluntariado; entre outros.

De acordo com a Lei o․ 9.790/99 nos seus art. $9^{\circ}$ e $10^{\circ}$, o termo de parceria designa o ajuste ou o acordo estabelecido entre o poder público e a OSCIP, destinado à 
formação de vínculo de cooperação entre as partes, para o fomento e a execução das atividades de interesse público por estas desempenhadas, tendo, como cláusulas essenciais, as determinadas no art. $10^{\circ}, \S 2^{\circ}$ e incisos seguintes. Observamos que $o$ termo de parceria é mais um instrumento alternativo às concessões e permissões de serviço público.

Assim, ao fazer do Estado um mero "parceiro", ou ainda um "Estado Contratual", ou mesmo um "Estado Financiador", constata-se um movimento no sentido de institucionalizar as OS e OSCIPs, na seara do Direito Administrativo, enquanto integrantes do terceiro setor. As discussões a respeito da transferência dos serviços sociais do estado para a sociedade civil denotam, fundamentalmente, uma forma de privatização, pois de acordo com Maria da Glória Gohn:

As Organizações Sociais (OSs) recebem recursos públicos consignados no orçamento da União ou do respectivo Estado, constituindo receita própria. A alocação dos recursos e a execução orçamentária das OSs não estão submetidas aos ditames da execução orçamentária, financeira e contábil, como os demais órgãos públicos, que têm de submeter-se a um controle processualístico. Seu controle se dá pelos seus resultados, por meio da avaliação das metas que ela estabeleceu. Além disso, as OSs recebem toda a infraestrutura montada que antes servia de base a um órgão estatal na prestação do serviço (GOHN, 2008, p. 99).

Uma questão que precisa ser observada é o controle social com relação às entidades do terceiro setor, pois o que se observa é que o estado, na maioria das vezes, repassa recursos físicos e financeiros a essas entidades, não exerce a correta fiscalização, favorece a sua criação, sob o argumento de que a execução das políticas sociais, principal campo de atuação dessas entidades, se tornou mais eficaz, tendo por base o discurso de que a esfera privada é mais eficiente do que a esfera pública.

Em síntese, a denominação tanto de OS como de OSCIPs refere-se às entidades privadas, fundações ou associações sem fins lucrativos, no qual são asseguradas vantagens e sujeições incomuns para as antigas pessoas jurídicas qualificadas pelo título de utilidade pública; essas passam a gozar de benefícios especiais não extensíveis às demais pessoas jurídicas privadas, isenções tributárias e vantagens administrativas diversas. A rigor, nenhuma entidade é constituída como OS nem tampouco, como OSCIPs. Ser considerada OS ou OSCIPs é uma qualidade adquirida, resultado de um ato formal de reconhecimento do poder público, facultativo e eventual, semelhante em muitos aspectos à qualificação deferida às instituições privadas sem fins lucrativos quando recebem o título de utilidade pública. Maria Sylvia Zanella Di Pietro afirma que "não há dúvidas de que as organizações sociais se constituem em um instrumento de privatização do qual o governo se utiliza para diminuir o tamanho do aparelhamento da Administração Pública” (DI PIETRO, 1999, p. 201). 
Em 2014, foi aprovado o chamado marco regulatório do terceiro setor por meio da Lei 13.019/2014, alterada pela Lei 13.204/2015, traz uma série de mudanças na relação entre Poder Público - em suas esferas e as Organizações da Sociedade Civil (OSCs). O principal defendido para a sua aprovação foi o de promover uma maior "profissionalização" do terceiro setor e uma política de ampliação dos incentivos fiscais para todas as entidades. Na tabela a seguir, é possível vislumbrar as principais diferenças entre as entidades do terceiro setor:

Tabela 1 - Diferenças entre as entidades do terceiro setor

\begin{tabular}{|c|c|c|}
\hline OS - Lei no 9.637/98 & OSCIP - Lei no 9.790/99 & OSC - Lei no 13.019/14 \\
\hline $\begin{array}{l}\text { Podem ser criadas por iniciativa } \\
\text { do Poder Público para absorver } \\
\text { órgãos extintos. }\end{array}$ & $\begin{array}{l}\text { Criadas exclusivamente por iniciati- } \\
\text { va de particulares. Em verdade, elas } \\
\text { vieram substituir o antigo modelo de } \\
\text { entidades de utilidade pública. }\end{array}$ & $\begin{array}{l}\text { Criadas por iniciativa do Poder Pú- } \\
\text { blico ou de particulares. Não subs- } \\
\text { tituem o modelo das OS e OSCIPS, } \\
\text { admite um novo sujeito - OSC. }\end{array}$ \\
\hline $\begin{array}{l}\text { Participação de representantes } \\
\text { do Estado e da Sociedade Civil } \\
\text { no órgão de deliberação superior } \\
\text { em proporção elevada em rela- } \\
\text { ção aos seus associados. }\end{array}$ & $\begin{array}{l}\text { Corpo decisório formado exclusi- } \\
\text { vamente pelos associados. A par- } \\
\text { ticipação do Estado se dá apenas } \\
\text { no acompanhamento gerencial dos } \\
\text { termos de parceria eventualmente } \\
\text { firmados. }\end{array}$ & $\begin{array}{l}\text { Comissão de Seleção, Monitoramen- } \\
\text { to e Avaliação e do Chamamento } \\
\text { Público. }\end{array}$ \\
\hline $\begin{array}{l}\text { Obrigatoriedade de se firmar o } \\
\text { Contrato de Gestão. }\end{array}$ & $\begin{array}{l}\text { Faculdade de se firmar o termo de } \\
\text { parceria em substituição ao tradicio- } \\
\text { nal convênio. }\end{array}$ & $\begin{array}{l}\text { Faculdade de firmar parceria com o } \\
\text { objetivo de promover atividade ou } \\
\text { projeto, termo de colaboração ou ter- } \\
\text { mo de fomento. }\end{array}$ \\
\hline $\begin{array}{l}\text { Publicação anual no Diário Ofi- } \\
\text { cial da União do relatório de exe- } \\
\text { cução do contrato de gestão, no } \\
\text { formato de relatório gerencial. }\end{array}$ & $\begin{array}{l}\text { Publicação anual da prestação de } \\
\text { contas da totalidade dos recursos } \\
\text { recebidos, públicos ou privados, no } \\
\text { formato tradicional. }\end{array}$ & $\begin{array}{l}\text { Publicação anual da prestação de } \\
\text { contas da totalidade dos recursos } \\
\text { públicos recebidos, no formato tradi- } \\
\text { cional. }\end{array}$ \\
\hline $\begin{array}{l}\text { Possibilidade de acumulação da } \\
\text { qualificação de utilidade pública } \\
\text { para todos os efeitos. }\end{array}$ & $\begin{array}{l}\text { Impossibilidade de acumular quali- } \\
\text { ficações. }\end{array}$ & $\begin{array}{l}\text { Impossibilidade de acumular qualifi- } \\
\text { cações. }\end{array}$ \\
\hline $\begin{array}{l}\text { Rol aberto e genérico de enti- } \\
\text { dades que podem se qualificar } \\
\text { como OS. }\end{array}$ & $\begin{array}{l}\text { Rol taxativo de entidades que não } \\
\text { podem se qualificar como OSCIPs. }\end{array}$ & $\begin{array}{l}\text { Rol amplo e específico de entidades } \\
\text { que podem se qualificar como OSC }\end{array}$ \\
\hline $\begin{array}{l}\text { Ausência de detalhamento das } \\
\text { atividades próprias da OS. }\end{array}$ & $\begin{array}{l}\text { Detalhamento das atividades a que } \\
\text { devem se dedicar as OSCIPs. }\end{array}$ & $\begin{array}{l}\text { Detalhamento meticuloso das ativi- } \\
\text { dades a que devem se dedicar as } \\
\text { OSC. }\end{array}$ \\
\hline Objetivos sociais mais restritos & Objetivos sociais amplos & Objetivos sociais mais amplos \\
\hline $\begin{array}{l}\text { Regramento mais específico, } \\
\text { que desce a minúcias sobre o } \\
\text { funcionamento. }\end{array}$ & $\begin{array}{l}\text { Regramento mais genéricos, sem } \\
\text { imposição de estruturas. }\end{array}$ & $\begin{array}{l}\text { Regramento específico, com imposi- } \\
\text { ção de estruturas. }\end{array}$ \\
\hline
\end{tabular}

Fonte: Santos (2008). Adaptada pelos autores. 
A lei $\mathrm{n}^{\mathrm{o}}$ 13.019/14, entrou em vigor, somente em janeiro de 2016, nos âmbitos da União, Estados e Distrito Federal. No entanto, para os Municípios foi estabelecido o início de sua vigência para $1^{\circ}$ de janeiro de 2017. A partir da aprovação do marco regulatório tem-se uma nova perspectiva na relação entre o poder público e as OSC, que passam a ser definidas como entidades privadas sem fins lucrativos, sociedade cooperativas e organizações religiosas (art. $2^{\circ}, \mathrm{I}, \mathrm{a}, \mathrm{b}$ e c), ampliando com isso, as possibilidades de realização de parcerias, com diversos sujeitos privados. Entretanto, conforme o Art. 30. A administração pública poderá dispensar a realização do chamamento público:

I - no caso de urgência decorrente de paralisação ou iminência de paralisação de atividades de relevante interesse público, pelo prazo de até cento e oitenta dias;

VI - no caso de atividades voltadas ou vinculadas a serviços de educação, saúde e assistência social, desde que executadas por organizações da sociedade civil previamente credenciadas pelo órgão gestor da respectiva política (Incluído pela Lei oํ 13.204, de 2015).

É possível observar, analisando o Art. $2^{\circ}$, VII, combinado com o Art. 30, referente às condições para a realização do chamamento público, que as Organizações da Sociedade Civil - OSC, deverão observar os princípios da administração pública, recepcionados pelo Art. 37, da Constituição Federal de 1988, pois de acordo com 0 art. $2^{\circ}$ do marco regulatório,

XII - chamamento público: procedimento destinado a selecionar organização da sociedade civil para firmar parceria por meio de termo de colaboração ou de fomento, no qual se garanta a observância dos princípios da isonomia, da legalidade, da impessoalidade, da moralidade, da igualdade, da publicidade, da probidade administrativa, da vinculação ao instrumento convocatório, do julgamento objetivo e dos que lhes são correlatos (grifos nossos).

Considera-se importante salientar que, mesmo que a atual legislação busque ampliar o controle social em relação às parcerias, e assim, adequando-se à própria perspectiva constitucional brasileira, as legislações que regulamentam as OS e as OSCIPS não foram revogadas perante a nova lei, sendo que ainda são mais utilizadas na formalização das parcerias público-privada na educação. Segundo tais normas, não possuem a garantia de um controle social efetivo, criando entraves e prejuízos para a democratização da educação pública, pois afasta do âmbito da atuação, bem como do controle, fiscalização e avaliação, o estado. Em comparação com as legislações das OS e das OSCIPs, o marco regulatório promoveu uma ampliação das possibilidades de atuação das entidades do terceiro setor, havendo como consequência que os direitos sociais passam a ser reconhecidos, em grande 
medida, sob o caráter de mercadoria ou sob o prisma da filantropia, concepções essas que se afastam do ideário da gestão democrática da educação, do exercício da cidadania e da emancipação social.

\section{Escola gerenciada por Organização da Sociedade Civil - OSC e subsidiada por fundos públicos: 0 exemplo da Escola Pequena Casa da Criança}

No final de 2017, a Secretaria Municipal de Educação (SMED) de Porto Alegre, amparada no novo marco regulatório das Organizações da Sociedade Civil, integrantes do terceiro setor, sob a justificativa de suprir um déficit de vagas na rede pública e de oferecer uma educação de melhor qualidade, assinou termo de colaboração com a Escola Pequena Casa da Criança para atividades de Educação Infantil e Ensino Fundamental. A Pequena Casa da Criança, conforme informações disponíveis em sua página na internet ${ }^{1}$ é uma instituição não governamental, sem fins lucrativos, filantrópica, educacional e de assistência social, de utilidade pública, que atua com base na doutrina e nos princípios cristãos, e prioriza a ação preventiva dirigida a crianças, adolescentes, família e idosos.

A instituição foi fundada em 15 de agosto de 1956 pela Congregação das Missionárias de Jesus Crucificado. Está localizada na comunidade Maria da Conceição, zona leste de Porto Alegre, e atende cerca de 600 crianças, jovens e idosos diariamente. Entre os objetivos da OSC está a promoção da educação integral por meio do ensino regular, profissionalizante e cursos livres de capacitação profissional, com vistas à melhoria da qualidade de vida dos atendidos. Consta em divulgação da entidade que, em 2019, a Pequena Casa da Criança foi aprovada no processo de avaliação dos princípios internacionais de Transparência e Boas Práticas Sociais da Phomenta, instituição que representa o Brasil no Comitê Internacional de Agências que monitoram ONGs no Mundo (ICFO). Sendo aprovada, a Pequena Casa recebeu o Certificado de Transparência e Boas Práticas Sociais.

Conforme dados da Secretaria Municipal de Educação de Porto Alegre, a entidade já atendia 350 crianças: 134 na educação infantil (maternal 2, jardim A e jardim B) e 216 do $1^{\circ}$ ao $5^{\circ}$ ano do ensino fundamental, no prédio da organização, localizado na rua Mario Aragão, 13, no bairro Partenon, Porto Alegre - RS, por meio de vagas compradas pelo município. Todavia, o contrato era renovado anualmente. Agora, com a assinatura do termo, a parceria terá vigência de 5 anos, renovável 
por igual período, e prevê um repasse mensal de até $R \$ 158$ mil do município para a entidade contratada.

De acordo com SMED, essa é a primeira escola charter de Ensino Fundamental de Porto Alegre. Abrams (2016) define escolas charter como instituições públicas, apoiadas por fundos públicos. No entanto, elas têm maior liberdade das regras e regulamentos estatais do que as escolas públicas tradicionais. Por exemplo, normalmente as escolas charter são livres para contratar ou demitir funcionários, professores, planejar currículos e promover valores específicos. Além disso, nos termos entre o órgão público e a escola charter devem estar claramente descritas as metas da escola, como a escola será administrada, a quantidade de dinheiro público que receberá e o grau de liberdade que será dado. A definição de Abrams (2016) por escola charter vai ao encontro dos questionamentos levantados por Adrião (2014) se não seriam muitas das parcerias público-privadas na educação brasileira, como essa em questão, uma modalidade charter, embora com outra nomenclatura, uma vez que para ser charter, define Adrião (2014), basta que não haja cobrança de mensalidades ou matrículas, que operem segundo as normas estabelecidas pelos setores responsáveis e que possam ser escolhidas pelas famílias.

Dessa forma, trataremos de explorar nesta seção, em especial, o termo de colaboração assinado entre o Município de Porto Alegre e a OSC Pequena Casa da Criança para a oferta de Educação Infantil e Ensino Fundamental, vislumbrando como os detalhes de parcerias como essa podem implicar na noção de escola enquanto bem público e democrático. Além disso, com base na literatura sobre escolas charter e modelos de descentralização da gestão escolar, característico dessas escolas, abordaremos as consequências dessa relação entre público e privado no que tangencia ao exercício docente, à gestão e às questões pedagógicas.

Por meio do Serviço de Informação ao Cidadão (E-Sic) da prefeitura de Porto Alegre, protocolamos solicitação de cópia do termo de colaboração assinado entre o município e a escola conveniada. Após 36 dias, a prefeitura forneceu o documento solicitado, o qual serve de base documental para a redação desta seção. Na figura que segue, que estampa a cláusula terceira do termo de colaboração, pode ser constatado o número de alunos atendidos e os repasses efetuados pela administração pública à OSC. 
Figura 1 - Cláusula terceira do termo de colaboração

\section{CLÁUSULA TERCEIRA - DOS RECURSOS FINANCEIROS}

3.1. A ADMINISTRAÇÃO PÚBLICA repassará a ORGANIZAÇÃO DA SOCIEDADE CIVIL, em 12 (doze) parcelas, o valor máximo mensal de $\mathrm{R} \$ \mathbf{1 5 8 . 4 8 5 , 5 0}$ (Cento e cinqüenta e oito mil, quatrocentos e oitenta e cinco mil e cinqüenta centavos), para o exercicio financeiro de 2018 , de acordo com o quadro abaixo:

\begin{tabular}{|l|l|l|l|}
\hline Valor de Refereancia & Horas de atendimento & No Atendimento & Valor Total \\
\hline $\begin{array}{l}\text { Educação Infantil } \\
\text { (Integral) }\end{array}$ & No mínimo 10 horas diárias. & 82 & $37.822,50$ \\
\hline $\begin{array}{l}\text { Educação } \\
\text { Infantil(regular) }\end{array}$ & No mínimo 04 horas diárias & 52 & $14.391,00$ \\
\hline $\begin{array}{l}\text { Ensino Fundamental } \\
\text { (regular) }\end{array}$ & No mínimo 04 horas diárias. & 216 & $106.272,00$ \\
\hline Total & & 350 & $158.485,50$ \\
\hline
\end{tabular}

Fonte: Termo de colaboração entre o município de Porto Alegre e a Pequena Casa da Criança.

Parcerias como esta implicam no tensionamento entre o que é público e o que é privado, comprometendo as próprias estatísticas educacionais, uma vez que os municípios contabilizam como pública a vaga contratada na instituição privada. Para Adrião (2008), esse movimento indica uma preocupante ampliação do atendimento à demanda custeada por recursos públicos, mas subsumida à ampliação e à disponibilidade do setor privado.

Conforme previsto no termo de colaboração assinado entre a prefeitura e a OSC Pequena Casa da Criança, a responsabilidade pela contratação dos professores, pela coordenação pedagógica e de finanças, bem como pelos serviços de limpeza e zeladoria, ficam sob responsabilidade da contratada. Tal prerrogativa fica reforçada na cláusula quinta do termo, quanto ao que compete à entidade. O item 5.2/ VII aborda essa responsabilidade, apontando como dever da OSC manter contrato de trabalho que assegure direitos trabalhistas, sociais e previdenciários aos seus trabalhadores e prestadores de serviços. 
Figura 2 - Cláusula quinta do termo de colaboração - itens VII e VIII

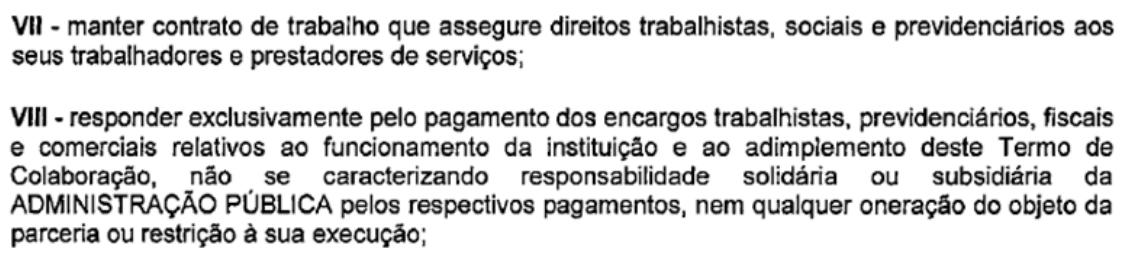

Fonte: Termo de colaboração entre o Município de Porto Alegre e a Pequena Casa da Criança.

Conforme dados da instituição, apresentados no relatório de atividades de 2018, os recursos humanos envolvidos na Escola de Ensino Fundamental contam com 01 diretora, 01 vice-diretora supervisora pedagógica, 01 coordenadora pedagógica, 01 secretária, 02 funcionários de higienização dos espaços, 01 professora de Atendimento educacional especializado, 02 professores de educação física (Educação infantil e Ensino fundamental), 02 professoras de reforço escolar, 07 professoras de educação infantil de 20 horas, 03 professoras de educação infantil de 40 horas, 03 professoras de ensino fundamental de 20 horas, 04 professoras de ensino fundamental de 40 horas, 01 assistente de ensino para o Ensino Fundamental, 06 profissionais de apoio para Educação Infantil. ${ }^{2}$

Com a autonomia para constituir seu quadro docente, a OSC pode contratar e demitir seus professores de acordo com critérios próprios de escolha, desvinculados de um plano de carreira e de atuação na perspectiva democrática da educação pública e da criação de uma identificação do profissional com o seu local de trabalho. Da mesma forma, as atividades de formação docente e pedagógica podem ser orientadas a partir dos preceitos da OSC contratada. Outros recursos, como materiais didáticos, assessoramentos e questões relacionadas à infraestrutura, também podem ser contratados pelo parceiro privado, com autonomia de escolha. Além disso, apesar de, obrigatoriamente, desenvolver um projeto político pedagógico em consonância com as Diretrizes Nacionais e as Orientações pedagógicas da SMED possui flexibilidade para orientar suas práticas a partir de valores específicos, como religiosos e culturais. Nesse caso, a OSC em questão, "atua com base na doutrina e nos princípios cristãos". ${ }^{3}$

Para a manutenção das atividades, além dos valores provenientes do município de Porto Alegre, os quais somaram cerca de R $\$ 3$ milhões entre 2017 e 2018, conforme mostra a planilha a seguir, a OSC possui outros parceiros também como fontes de recursos, conforme consta no seu site. ${ }^{4}$ Em seus balancetes contábeis 
disponíveis ao público geral, a entidade divulga a sua receita operacional, conforme estabelecido no próprio termo de colaboração com o município de Porto Alegre, para dar publicidade acerca dos gastos com os recursos oriundos dos cofres públicos.

Figura 3 - Relatórios contábeis de receita

\section{Receita Operacional}

A receita operacional resulta das operaçб̃es a seguir:

Receita Operacional 2018 2017

Convênio de Projetos Assistência Social

$1.320 .160,87$

$1.693 .402,50$ $1.577 .777,96$

Receita de Educação/Convênio Pref. Mun.

$499.686,11$

$1.330 .860,00$

Convênio com Projetos Jovem Aprendiz

$510.776,30$

$458.123,21$

Convênio com Projetos

$19.942,41$

Receita com Eventos

$1.132 .590,80$

$88.650,93$

Receita com Doações

$337.450,01$

$19.942,41$

Outras Receitas

$(16.931,74)$

$898.101,88$

(-) Deduções da Receita

$5.477 .134,85$

Total

Fonte: Disponível em: http://www.pequenacasa.org.br/transparencia-e-governanca/. Acesso em: 24 ago. 2019.

Conforme a Secretaria de Educação, essa parceria foi uma saída encontrada para atender ao déficit na oferta de vagas na rede pública municipal. Porém, o histórico dos valores mostra um montante razoável para expandir as estruturas físicas da rede municipal ou a até mesmo a sua ampliação por meio de novas escolas. Porém, essa parece não ser a intenção da atual gestão do município. Pelo contrário, em suas declarações à imprensa, o secretário municipal de educação, Adriano Naves de Brito, tem ratificado a intensão de expandir esse modelo de convênios.

Em entrevista à Rádio Gaúcha, em 19 de fevereiro de 2018, Naves de Brito foi questionado sobre por que não ampliar a oferta na rede pública. Em sua resposta, considerou preferir ampliar esse modelo de parceria, argumentando que as vagas privadas podem ser oferecidas de forma mais rápida, já que não dependem da realização de concursos públicos para professores e da construção de novos prédios. "Tem uma questão financeira, de economizar recursos, mas não é só isso. O principal é que é um novo modelo de ensino, aumentando a pluralidade do ecossistema educacional do município. Teremos a possibilidade de comparar e saber qual funciona melhor (se é a escola pública ou a parceira)", ${ }^{5}$ afirmou Naves de Brito. 
Esse discurso em defesa da colaboração com o setor privado e das virtudes de tais parcerias consolida a posição de Laval (2004), que sustenta a perspectiva de que processos de descentralização da gestão escolar podem ser muito mais associados a um avanço em direção à constituição de um mercado escolar do que, propriamente, em direção a uma intensificação da democracia nos estabelecimentos e da melhora na qualidade da educação. Conforme Laval (2004, p. 158), "é em nome da concorrência, do papel do consumidor, da eficácia, da redução dos custos, da colaboração escola-empresa, que a descentralização é, na maior parte do tempo, exaltada”.

A concretização e a ampliação desse modelo de escola conveniada, que permite uma clara comparação ao modelo charter, ao invés de trazer os resultados positivos, teoricamente expressos por meio de indicadores de larga escala, pode consolidar um claro aumento da desigualdade de condições de aprendizagem e segregação escolar. Apesar de ser um projeto piloto da prefeitura de Porto Alegre, o cenário educacional e político nacional aponta para uma aposta significativa nessa modalidade de oferta da educação básica, justamente argumentando a redução de custos do estado e o aumento da qualidade do ensino. Todavia, tomando a amplitude em que tais parcerias se consolidaram em outros países que apostaram fortemente na modalidade charter, é legítimo e necessário apontarmos para os efeitos negativos dessas parcerias, já amplamente relatados nos estudos de Abrams (2016) sobre experiência americana e de Bunar (2012) sobre o sistema educacional Sueco, conforme já indicamos no início deste texto.

Tomando essas proporções maiores e exemplos de países como Estados Unidos, Suécia e a própria França, Laval (2004) considera que a desigualdade frente à escola não é mais somente fruto de uma seleção pela escola. Ela é o resultado das condições desiguais de escolha da escola. Se antes existia uma escola pública cuja qualidade e igualdade de condições de aprendizagem deveria ser assegurada a todos, a lógica das escolas charter é a da disputa por alunos, pelo prestígio social e, consequentemente, pela escolha dos pais.

Nesse sentido, a liberdade de escolha que a lógica do mercado encerra não é, decerto, a escolha de todos. Daí deriva uma grande variável de acordo com as classes sociais, não permitindo que se igualem as condições de ensino. Se os pais das classes médias, por exemplo, privilegiavam na sua escolha o sucesso escolar, por outro viés, os pais dos meios populares apresentam uma tendência a escolha de um estabelecimento no qual seus filhos "se sentiriam mais à vontade", escolhendo estabelecimentos onde os jovens da mesma origem seriam majoritários (LAVAL, 2004). 
Além disso, os pais de classes populares não conseguem entrar no quadro imposto pela lógica da escolha. Eles percebem as escolas como sendo bastante semelhantes umas às outras e limitam seu horizonte às escolas próximas. Diante dessa realidade, Laval (2004) considera que a "livre escolha" é uma obrigação de escolher e não uma liberdade da qual os pais disporiam naturalmente ou à qual eles teriam sempre aspirado. É uma obrigação feita a "jogadores” mais ou menos de acordo em "jogar" o jogo da competição de todos contra todos, quer eles queiram ou não. Esse contexto legitima o risco de que cada vez menos pessoas, inclusive professores, acreditem ser ainda possível fazer uma "escola comum", misturando jovens de diferentes classes sociais.

No contexto dessas parcerias, Dardot e Laval (2016) consideram que toda a reflexão sobre a administração pública adquire um caráter técnico, em detrimento das considerações políticas e sociais que permitiriam evidenciar tanto o conceito da ação pública como a pluralidade das opções possíveis. Essa prerrogativa afeta diretamente a própria concepção dos bens públicos bem como os princípios regentes de sua distribuição.

A igualdade de tratamento e a universalidade dos benefícios são questionadas tanto pela individualização do auxílio e pela seleção dos beneficiados, na qualidade de amostras de um "público-alvo", quanto pela concepção consumista do serviço público (DARDOT; LAVAL, 2016, p. 380).

Além desse distanciamento das características democráticas originais de uma escola pública, outro fator merece a nossa atenção. Como bem abordado por Pichonelli (2019), apesar de o Supremo Tribunal Federal (STF) ter reiterado em setembro de 2018 que, com a atual legislação, os pais não têm direito de tirar filhos da escola para ensiná-los exclusivamente em casa, prática conhecida como educação domiciliar (ou "homeschooling", no termo em inglês), proposta que ganhou força no governo Bolsonaro. Segundo o autor, sob uma série de alegações pouco ou nada fundamentadas cientificamente, o governo tenta regulamentar uma proposta de educação que está mais para atender aos interesses dos empresários da educação e de grupos religiosos do que propriamente a oferecer uma educação de melhor qualidade.

Os defensores do ensino domiciliar elegem como principal argumento para a defesa dessa modalidade de ensino que, dessa forma, as crianças estariam livres de doutrinação e poderiam receber uma educação de acordo com os valores culturais e religiosos da sua família. Nesse sentido, não serviriam essas parcerias entre o Poder Público e o terceiro setor uma alternativa ao homeschooling? Embora a 
educação não aconteça no berço familiar, os pais poderiam escolher matricular os filhos em uma escola alinhada política, religiosa e ideologicamente à família, considerando que, normalmente, as escolas charter são livres para desenvolver suas atividades orientadas por valores específicos. O próprio termo de colaboração ora analisado é estruturado, como já apontamos, a partir do novo marco regulatório, firmado entre o Poder Público e uma instituição religiosa, do terceiro setor, que atua com base na doutrina e nos princípios cristãos.

\section{Algumas consideraç̃oes}

No atual momento político brasileiro, as parcerias entre o Poder Público e Organizações da Sociedade Civil integram as propostas de muitos governantes orientados por uma racionalidade neoliberal. Como já abordamos, a partir da aprovação do novo marco regulatório tem-se uma nova perspectiva na relação entre o Poder Público e as OSC, que passam a ser definidas como entidades privadas sem fins lucrativos, sociedade cooperativas e organizações religiosas. Dessa forma, tem razão Adrião (2014) quando questiona se não seriam as escolas "conveniadas" brasileiras, uma modalidade de charter, mesmo vivenciando essa experiência com outra designação, para a qual as desigualdades observadas em outros países, também devem ser objeto de estudos na realidade brasileira.

A preocupação de Adrião (2014) pode ser atestada quanto observada, por exemplo, a crítica lançada por Bunar (2012) sobre o modelo educacional da Suécia, que apostou em uma descentralização e nas escolas charter, crítica que também se comprova com dados do relatório da OCDE de 2010. Conforme o relatório, vinte anos depois de sua implantação, é possível observar que os custos do sistema educacional sueco não diminuíram, que as notas nas escolas de ensino fundamental e médio estão em constante declínio e que a Suécia perdeu terreno em estudos comparativos internacionais, como o PISA e o TIMSS (OCDE, 2010). Esses dados fazem perder sustentação o argumento de muitos gestores, de empresários da educação e de políticos, de que a iniciativa privada oferece uma educação com mais qualidade do que a esfera pública.

No caso específico que analisamos neste estudo, é oportuno considerar que não se trata de questionar a OSC Pequena Casa da Criança quanto à sua atuação. Pelo contrário, as informações disponíveis apontam para uma instituição séria e comprometida com suas funções, digna dos diversos prêmios de transparência e responsabilidade social que tem conquistado. O que está em jogo, e essa é nossa 
crítica, é a concepção de escola republicana, enquanto bem público, e o flerte com a iniciativa privada, sob a pretenciosa intenção de associar a escola a uma empresa, os alunos a clientes e a educação a uma mercadoria, um bem de consumo.

É oportuno destacarmos que sob esta ótica, Ball e Youdell (2007) consideram que não se trata do abandono por parte do estado do controle que ele exerce sobre os serviços públicos de educação, mas o estabelecimento de uma nova forma de controle ou de uma redução controlada desse controle, o que favorece a descentralização e a perpetração do setor privado sobre o público. Isso só é possível, segundo Akkari (2011), com o declínio da qualidade das escolas públicas; desenvolvimento da educação permanente por meio de políticas públicas ou por empresas (subsídios para a formação continuada); homogeneização dos conteúdos de ensino, permitindo o aumento do mercado de livros didáticos e softwares.

Reforçamos nossa constatação de que o marco regulatório promoveu uma ampliação das possibilidades de atuação das entidades do terceiro setor. Nesse sentido, a ampliação de parcerias da esfera pública com o terceiro setor tem permitindo que, sob o prisma da filantropia, direitos sociais consolidados, como a educação pública de qualidade para todos, sejam gradativamente afastados do ideário da gestão democrática da educação, do exercício da cidadania e da emancipação social.

Dessa forma, concordamos com Adrião (2008) que estas parcerias ocorrem menos como alternativa democratizadora, com vistas ao atendimento criativo das especificidades de comunidades e dos interesses das faixas etárias atendidas pela escola básica e mais como mecanismo de ampliação do mercado educacional. Esse tipo de política, como expressado por Adrião (2008, p. 8), "além se não resultar de discussões com a comunidade escolar, dado ser definida em função de um padrão construído pelo agente privado, redefine o espaço do público e minimiza sua autonomia diante do privado".

Esse modelo de gestão educacional baseada em princípios do mercado retoma o que Ball e Youdell (2007) definem como prática que objetiva atrair clientes, ocasionais e regulares, com ênfase sobre a atribuição de recursos àqueles considerados mais aptos. As avaliações são restritas do mérito, com base na contribuição dos indicadores de desempenho e a educação das crianças é avaliada com base nos custos e resultados. Esse modelo abre espaço para a performance individual das escolas e dos alunos, para processos de diferenciação e hierarquias, de canalização, seleção e exclusão, representando um grande risco ao princípio democrático de educação, de caráter igual e acessível a todos. 
Considerando o exposto neste estudo, a denúncia de Adrião (2014) de que essas parcerias podem ser consideradas modalidades de escolas charter, mesmo sob outra designação, merece a atenção e estudos que se debrucem sobre "a natureza e as consequências para a extensão do direto à uma educação de qualidade de todos os programas governamentais que transfiram a gestão da educação para setores privados" (p. 279). Na perspectiva da educação e da escola pública, essa inquietação legitima, sobretudo, a preocupação pela manutenção de uma educação como direito humano e bem comum.

\section{Notas}

1 Disponível em: http://www.pequenacasa.org.br/quem-somos/. Acesso em: 06 ago. 2019.

2 Relatório de atividades disponível em: http://www.pequenacasa.org.br/wp-content/uploads/2019/05/Relatório-de-Atividades-2018.pdf. Acesso em: 24 ago. 2019.

3 Disponível em: http://www.pequenacasa.org.br/quem-somos/. Acesso em: 24 ago. 2019.

4 Ver: http://www.pequenacasa.org.br/parceiros/. Acesso em: 24 ago. 2019.

5 Conteúdo disponível em: https://gauchazh.clicrbs.com.br/porto-alegre/noticia/2018/02/prefeitura-de-porto-alegre-faz-primeira-parceria-com-escola-privada-de-ensino-fundamental-saiba-como-funciona-cjds2y7am02j101rvhpzklnzs.html. Acesso em: 24 ago. 2019.

\section{Referências}

ABRAMS, Samuel E. Education and the Commercial Mindset. Cambridge, Massachusetts: Harvard University Press, 2016.

ADRIÃO, Theresa. Escolas charters nos EUA: contradições de uma tendência proposta para o Brasil e suas implicações para a oferta da educação pública. Educação e Filosofia Uberlândia, v. 28, n. especial, p.263-282, 2014.

ADRIÃO, Theresa. Sistemas apostilados de ensino e municípios paulistas: o avanço do setor privado sobre a política educacional local. In: Anais do V Simpósio internacional: o estado e as politicas educacionais no tempo presente. UFU/Uberlândia, 2008.

AKKARI, Abdeljalil. Internacionalização das políticas educacionais: transformações e desafios. Petrópolis - RJ: Vozes, 2011.

BALL, Stephen J; YOUDELL, Deborah. Privatización encubierta en la educación pública. In: Anais do V Congreso Mundial de la Educación. 2007.

BRASIL. Lei n ${ }^{\circ}$ 9.637, de 15 de maio de 1998. Dispõe sobre a qualificação de entidades como organizações sociais, a criação do Programa Nacional de Publicização, a extinção dos órgãos e entidades que menciona e a absorção de suas atividades por organizações sociais, e dá outras providências. Brasília, DF, 1998. 
BRASIL. Lei Federal nำ 9.790, de 23 de março de 1999. Dispõe sobre a qualificação de pessoas jurídicas de direito privado, sem fins lucrativos, como Organizações da Sociedade Civil de Interesse Público, institui e disciplina o Termo de Parceria, e dá outras providências. Brasília, DF, 1999.

BRASIL. Lei Federal no 13.019, de 31 de julho de 2014. Estabelece o regime jurídico das parcerias entre a administração pública e as organizações da sociedade civil, em regime de mútua cooperação, para a consecução de finalidades de interesse público e recíproco, mediante a execução de atividades ou de projetos previamente estabelecidos em planos de trabalho inseridos em termos de colaboração, em termos de fomento ou em acordos de cooperação; define diretrizes para a política de fomento, de colaboração e de cooperação com organizações da sociedade civil; e altera as Leis $\mathrm{n}^{\text {os }} 8.429$, de 2 de junho de 1992, e 9.790, de 23 de março de 1999. Brasília, DF, 2014.

BRUNO, Lucia. Gestão da Educação: Onde Procurar o Democrático? In. OLIVEIRA, Dalila Andrade; ROSAR, Maria de Fatima Felix (org.). Política e Gestão da Educação. Belo Horizonte: Autêntica, 2002.

BUNAR, Nihad. Parents and teachers on local school markets: Evidence from Sweden. Working Paper 208, National Center for the Study of Privatization in Education, Teachers College, Columbia University, 2012.

DARDOT, Pierre; LAVAL, Christian. A Nova Razão do Mundo: ensaio sobre a sociedade neoliberal. Trad. Mariana Echalar. São Paulo: Boitempo, 2016.

DI PIETRO, Maria Sylvia. Parcerias na Administração Pública. 3. ed. São Paulo: Atlas, 1999.

EDWARDS JR, D. Brent; HALL ,Stephanie M. Colombian Charter School Management. Working Paper 234, National Center for the Study of Privatization in Education, Teachers College, Columbia University, 2017.

ELACQUA, Gregory. The impact of school choice and public policy on segregation: Evidence from Chile. Working Paper 185, National Center for the Study of Privatization in Education, Teachers College, Columbia University, 2010.

GIDDENS, Anthony. A Terceira Via. Reflexões sobre o Impasse Político Atual e o Futuro da Socialdemocracia. Rio de Janeiro: Record, 2001.

GOHN, Maria da Glória. Conselhos municipais de acompanhamento e controle social em Educação: participação, cidadania e descentralização. In. SOUZA, Donaldo Bello de. (org). Conselhos municipais e controle social da educação: descentralização, participação e cidadania. São Paulo: Xamã, 2008.

LAVAL, Christian. A Escola não é uma Empresa: o neoliberalismo em ataque ao ensino público. Trad. Maria Luiza M. de Carvalho e Silva. Londrina: Planta, 2004.

ORGANIZATION FOR ECONOMIC CO-OPERATION AND DEVELOPMENT - OECD. $M a$ king reform happen: lessons from OECD countries. Paris: OECD Publishing, 2010.

ORGANIZAÇÃO DE COOPERAÇÃO E DESENVOLVIMENTO ECONÔMICO - OCDE. Fazendo a reforma acontecer: lições dos países da OCDE. Paris: OCDE, 2010. 
PICHONELLI, Matheus. Hommeschooling e a domesticação do aluno. In.: CASSIO, Fernando (org.). Educação contra a barbárie: por escolas democráticas e pela liberdade de Ensinar. São Paulo: Boitempo, 2019.

PREFEITURA MUNICIPAL DE PORTO ALEGRE. Termo de colaboração que entre si celebram o Município de Porto Alegre e Pequena Casa da Criança em regime de mútua cooperação para execução de atividades de Educação Infantil e Fundamental no Município de Porto Alegre. Porto Alegre, 2017.

SARDINHA, Rafaela Campos. O Projeto Procentro e as escolas charter: investigação de um modelo educacional defendido pela Fundação Itaú Social. Dissertação (Mestrado em Esducação) Universidade Federal do Rio de Janeiro, Centro de Filosofia e Ciências Humanas (CFCH), Rio de Janeiro, 2013.

SANTOS, Enoque Ribeiro. As OSCIP (Organizações da Sociedade Civil de Interesse Público) e a Administração Pública - intermediação fraudulenta de Mão-de-Obra sob uma roupagem jurídica. Revista de Direito Administrativo no 26: Rio de Janeiro, p. 10. fev.,2008.

PEQUENA CASA DA CRIANÇA. Disponível em http://www.pequenacasa.org.br. Acesso em: 24 ago. 2019. 